\title{
The toll of noninfected CRS patients to the COVID-19
}

\section{pandemic*}

\author{
Ludger Klimek', Jan Hagemann², Ali Alali', Magdalena Spielhaupter ${ }^{3}$, \\ Tilman Huppertz ${ }^{2}$, Karl Hörmann ${ }^{4}$, Christoph Matthias² \\ ' Centre for Rhinology and Allergology, Wiesbaden, Germany \\ ${ }^{2}$ Department of Otorhinolaryngology, Head and Neck Surgery, University Medical Center, Mainz, Germany \\ 3 ORL Clinic, Taunusstein, Germany \\ ${ }^{4}$ Mannheim University Hospital, Mannheim, Germany
}

Rhinology 58: 5, 522 - 523, 2020

https://doi.org/10.4193/Rhin20.250

*Received for publication:

May 21, 2020

Accepted: June 23, 2020

\section{To the Editor:}

Social distancing with the aim of avoiding infections and preserve critical care capacities during the COVID-19 pandemic has been implemented in Germany according to World Health Organization (WHO) recommendations ${ }^{(1)}$ from early March onwards. Limitations of physical contacts to reduce exposure to SARSCoV-2 infected individuals were handled strictly, particularly in medical centers dealing with airway diseases, like rhinology and pneumology clinics. Such measures and reluctance to visit outand inpatient services resulted in a $82 \%$ decrease in consultations to the 12 German oto-rhino-laryngological (ORL) centres forming our database during the 50 days following March 09 in 2020 if compared to the same period in 2019 ( $n=3.547$ vs. $\mathrm{n}=19.783 ; \mathrm{p}<0.01$ ). Follow-up consultations in known CRS patients were $78 \%$ less and new CRS patient consultations reduced by even $93 \%$. CRSwNP disease severity (visual analogue scale 0-10cm; mean (SD)) increased from 6.09 (1.47) to 7.91 (1.18) ( $p<0.05$ ). Our data show a decline of sinus surgery by $96 \%$, since only emergency cases were to be performed. Regarding future procedures, $71 \%$ fewer indications were given and appointments made for sinus surgery. At the same time, complications in CRS increased fourfold (from 6 to 22 ( $p<0.01$ ), but due to the low absolute numbers for e.g. endocranial complications 0 vs 1 (n.s.), (peri-)orbital abscesses 2 vs $6(p<0.01)$, osseous complications 1 vs $7(p<0.01)$. This might be ascribed to Gaussian noise and may not imply causality.

Total use of systemic corticosteroids (SCS) that are discussed to be an independent risk factor for COVID-19 (2) increased fourfold (mean daily prednisolone equivalent per $100 \mathrm{CRS}$ patients from $23.4 \mathrm{mg}$ to $103.8 \mathrm{mg} ; \mathrm{p}<0.01$ ), as did use of intravenous antibiotics (mean recommended daily dose per 100 CRS patients from 0.92 to $3.46 ; p<0.01)$.

Injections of Dupilumab almost came to a complete standstill. Dupilumab, a monoclonal antibody directed against the alpha subunit of the IL-4 receptor (IL-4Ra), thus acting as a dual antagonist of both IL-4 and IL-13 signaling pathways and T2 type inflammation was the first biological therapy that received regulatory approval in the EU and the US. Dupilumab is authorized in Europe as an add-on therapy to intranasal corticosteroids for the treatment of adults with severe CRSwNP, that cannot be adequately controlled with systemic corticosteroids and/or surgical intervention. Being reimbursed in Germany for CRSwNP since end of 2019, we started therapy with this biological in $\mathrm{n}=78$ patients in the 50 days before the lockdown, but in only 9 new patients in the same time frame, thereafter.

Our data on CRS care underline reports on undertreatment of non-COVID-19 individuals with several different diseases during the current pandemic ${ }^{(3)}$.

We should try to reduce the toll these patients have to pay as much as possible. In our experience, telemedicine is a way to cope this situation ${ }^{(4,5)}$. Telemedicine training for self-injections of Dupilumab and subsequent patient monitoring is one of several fields of application in CRS ${ }^{(6)}$. We established telemedicine, e-Health and artificial intelligence-supported triage for selecting the right patients for onsite-consultations and to advise patients in several demands ${ }^{(6)}$. In an attempt to reduce collateral damage until calculated risk-benefit analyses are possible such approaches are needed in the COVID-19 pandemic. Sharing of knowledge may allow us to keep the high-quality standards of our health care in CRS patients.

\section{Conflict of interest}

We declare no competing interests.

\section{Authorship contribution}

LK and JH drafted the manuscript. AA, MS performed data collection and analysis. $\mathrm{TH}, \mathrm{KH}$ and $\mathrm{CM}$ edited the manuscript. 


\section{Acknowledgement}

We acknowledge our study assistants and nurses, which included a team of Center for Rhinology and Allergology, Mainz University Hospital and Allergiezentrum Rheinland-Pfalz, Germany.
Source of financial support or funding: This work was supported by a grant from the Hessische Stiftung für Prävention, Wiesbaden, Germany (HSP 2020/05-2).

\section{References}

1. World Health Organization. Coronavirus disease (COVID-19) technical guidance: Patient management. 2020.

2. Bousquet J, Akdis C, Jutel M, et al. Intranasal corticosteroids in allergic rhinitis in COVID19 infected patients: An ARIA-EAACI statement. Allergy. 2020;10.1111/all.14302. doi:10.1111/all.14302.

3. Rosenbaum L. The Untold Toll - The Pandemic's Effects on Patients without Covid-19. New Eng J Med. 2020 Jun 11;382(24):2368-2371.

4. Klimek L, Jutel M, Akdis C, Bousquet J, Akdis M, Bachert $C$, et al. Handling of allergen immunotherapy in the COVID-19 pandemic: An ARIA-EAACI statement. Allergy. 2020;10.1111/all.14336. doi:10.1111/ all.14336
5. Matricardi PM, Dramburg S, Alvarez-Perea A, et al. The role of mobile health technologies in allergy care: An EAACl position paper. Allergy. 2020;75(2):259-72

6. Klimek L, Becker S, Buhl R, et al Positionspapier: Empfehlungen zur Behandlung der chronischen Rhinosinusitis während der COVID-19-Pandemie im deutschen Gesundheitssystem Empfehlungen des Ärzteverbandes Deutscher Allergologen (AeDA) und der Deutschen Gesellschaft für HNO-Heilkunde, Kopf- und Halschirurgie (DGHNOKHC) Diese Empfehlungen basieren auf dem EAACI Positionspapier "Treatment of chronic RhinoSinusitis with nasal polyps (CRSwNP) in the COVID-19 pandemics - An EAAC Position Paper",. Laryngorhinootologie. 2020;99(6):356-364.

\section{Dr. Jan Hagemann}

Department of Otolaryngology

Head and Neck Surgery

Universitaetsmedizin Mainz

Langenbeckstr. 1

55131 Mainz

Germany

Tel +49-6131-17 2440

E-mail:

Jan.Hagemann@unimedizin-mainz.

de 